\title{
Simulation of Mixed Power Generation and Absorption Cooling System
}

\author{
Aref Naimzad, Murtaza Omid
}

\begin{abstract}
Paper The energy shortage in today's world has shifted the view of researchers to the optimal use of available energy, and experts from energy research centers have always taken steps to achieve this important issue. In the present study, the focus is on the simulation of a mixed system which, in addition to generating power, uses the heat dissipated from its chimney to produce cooling using an absorption chiller. This mixed system is simulated in EES software. The performance of the mixed system is examined in three different views, and in each view, the values of cold loads are obtained from the absorption chiller.
\end{abstract}

Keywords: Absorption, Chiller, Energy, Heat dissipation, Power

\section{INTRODUCTION} solution to reduce energy consumption and reduce environmental pollutants in developed countries. Research centers of these countries are working on energy optimization and management. Among these, one of the most important energy optimization strategies performed in all these countries with the aim of increasing the efficiency of energy production and optimal use of fuel resources with an overall production systems of cooling, heating and electricity.

The simultaneous generation of electricity and heat technologies generate electricity or mechanical power and significantly recycle excess heat for a variety of uses, including heating and cooling.

Much researches has been done on the simulation of mixed power generation systems, including the article by Salcedo et al (2011), which examines the economics and environmental aspects of mixed Rankin and Water System and The power supply system is covered using a solar collector[1]. This article uses weather data from Tarragona, Spain.

Sanaye et al. (2013) presented an energy, economics, and environmental analysis plan for a mixed cycle in which evaluations and research were performed by multitasking and Pareto method (Wilfredo Pareto 1948-1848 Italy)[2].

Alzahrani et al. (2014) investigated the combined electricity generation system with industrial data with

Revised Manuscript Received on August 13, 2020.

* Correspondence Author

Aref Naimzad*, Mechanical Engineering Department, Engineering Faculty, Kabul University, Kabul, Afghanistan. E-mail: naimzad@ku.edu.af

Murtaza Omid, Research \& Development Department, Green Energy Research Center, Kabul, Afghanistan. E-mail: omidmurtaza@yahoo.com

(c) The Authors. Published by Blue Eyes Intelligence Engineering and Sciences Publication (BEIESP). This is an open access article under the CC BY-NC-ND license (http://creativecommons.org/licenses/by-nc-nd/4.0/)
Energy optimization has been proposed as a basic efficiency of 75 to $90 \%$, and the use of simultaneous

thermal vapor density (TVC) in terms of energy balancing and the effects of various parameters in the power generation system including pressure ratio and turbine inlet temperature [3]. They concluded that a major irreversibility occurs in the combustion chamber. Loutatidou et al. (2015) simulated a low enthalpy earth heating system with reverse osmosis desalination and multi-stage distillation, and concluded from economic analysis that in the Persian Gulf zone, the combination of the earth heating system with reverse osmosis is more economical than combining geothermal systems with multi-stage distillation, and the operating life of the systems was also examined[4]. Gabriel et al. (2016), provided an overview of the power generation process and water production capacity, and used the plant's excess heat as input heat to the mixed electricity and freshwater production system [5]. They economically analyzed the cost-effectiveness by optimizing the mathematical formulas. Mokhtari et al. (2016) simulated a mixed gas and fresh water turbine system and showed that it would save costs [6].

Wang (2014) investigated on a simultaneous generation system based on a polymer fuel source and studied the effect of key parameters such as inlet gas mass, cooling water mass and source operating temperature on system performance[7].

Taheri et al.(2014) studied the system of simultaneous production of fresh water from saline, electricity and cooling and designed an optimal cycle to use low pressure steam to produce fresh water, electricity and cooling[8].

Tavakuli et al. (2016) studied the simultaneous generation of electricity, heating and cooling systems by studying and comparing the prices of energy carriers using the balance and demand of energy through genetic algorithm [9].

In the current research, first the simulation has done for gas power generation unit, and the estimation of output heat lost studied. Then, the simulation has made for the cooling production system using absorption chiller. Finally, the mixed power generation and cooling system is discussed in different views.

\section{THE GOVERNING EQUATIONS}

\section{A. Gas turbine cycle}

The gas turbine cycle is modeled by the relations of the first law of thermodynamics.

As shown in Figure 1, air enters the compressor under environmental conditions (point 1) and after compression (point 2) is sprayed with fuel into the combustion chamber and explodes.

Published By:
Blue Eyes Intelligence Engineering \& Sciences Publication (C) Copyright: All rights reserved. 


\section{Simulation of Mixed Power Generation and Absorption Cooling System}

The combustion gases are then removed from the combustion chamber (point 3) and electricity is generated by passing through the gas turbine (point 4). Gas cycle losses occur mainly in three main components: compressor, combustion chamber and gas turbine.

For irreversibility calculations in each component, each of them must be considered as a control volume. The energy balance and the governing equations for components of this cycle are as follows [10]:

Compressor:

$$
\begin{gathered}
\eta_{\text {com }}=\mathrm{w}_{\mathrm{com}, \mathrm{s}} / \mathrm{w}_{\mathrm{com}, \mathrm{a}} \\
\mathrm{w}_{\mathrm{com}}=\mathrm{h}_{2}-\mathrm{h}_{1} \\
\mathrm{p}_{2}=\mathrm{r}_{\mathrm{a}} \times \mathrm{p}_{1}
\end{gathered}
$$

Where $r_{a}$ is the compressor pressure ratio.

Combustion chamber:

$\dot{\mathrm{m}}_{\mathrm{a}} \mathrm{h}_{2}+\dot{\mathrm{m}}_{\mathrm{f}} \mathrm{LHV}=\dot{\mathrm{m}}_{\mathrm{g}} \mathrm{h}_{3}+\left(1-\eta_{\mathrm{cc}}\right) \dot{\mathrm{m}}_{\mathrm{f}} \mathrm{LH}$

$\mathrm{p}_{3} / \mathrm{p}_{2}=\left(1-\Delta \mathrm{p}_{\mathrm{cc}}\right)$

$\dot{\mathrm{m}}_{\text {gas }}=\dot{\mathrm{m}}_{\text {air }}+\dot{\mathrm{m}}_{\mathrm{f}}$

In these equations $\dot{m}_{f}$ is the fuel mass, $\dot{m}_{g}$ is the mass of the products $\eta_{c c}$ is the efficiency of the combustion chamber, $\Delta \mathrm{p}_{c e}$ is the pressure reduction inside the combustion chamber.

Gas turbine:

$\eta_{G T}=\frac{h_{3}-h_{4}}{h_{3}-h_{4 S}}=\frac{T_{3}-T_{4}}{T_{3}-T_{4 S}}$

$\mathrm{W}_{\mathrm{tur}}=\mathrm{h}_{3}-\mathrm{h}_{4}$

$\mathrm{W}_{\text {net }}=\mathrm{W}_{\text {tur }}-\mathrm{W}_{\text {comp }}$

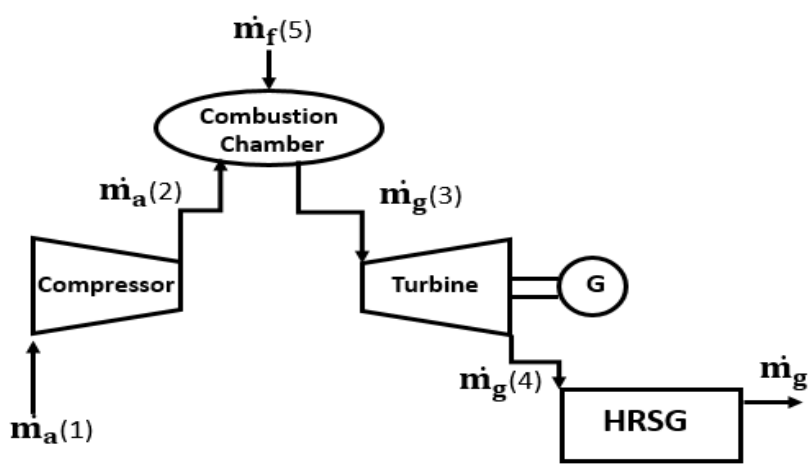

Fig.1. Gas-turbine Steam generator system

\section{B. Steam generator of heat recycling}

The considered recycle boiler in this cycle is a single pressure recycle boiler which consists of two parts, economizer and evaporator. The feed water first enters the economizer and its temperature rises to saturation temperature. It then enters the evaporator and its vapor quality reaches one at constant temperature and pressure. Some of this steam is used for absorption chillers.

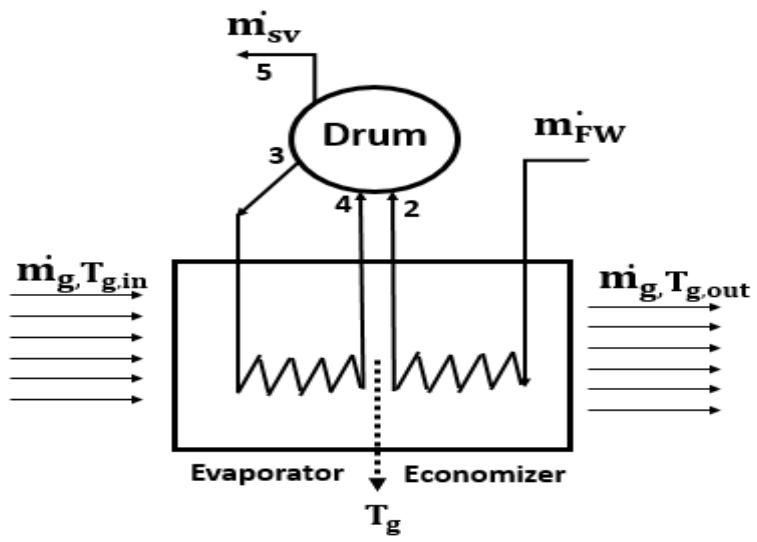

Fig.2. Steam generator of recycled heat [11]

The energy balance for the assumed recycle boiler in figure (2) is as follows [11]:

$\dot{\mathrm{m}}_{\mathrm{sv}} \mathrm{h}_{\mathrm{fg}}=\dot{\mathrm{m}}_{\mathrm{g}} \mathrm{cpg}\left(\mathrm{T}_{\mathrm{gin}}-\mathrm{T}_{\mathrm{g}}\right)$

$\dot{\mathrm{m}}_{\mathrm{sv}} \mathrm{cp}_{1}\left(\mathrm{~T}_{2}-\mathrm{T}_{1}\right)=\dot{\mathrm{m}}_{\mathrm{g}} \mathrm{cp}_{\mathrm{g}}\left(\mathrm{T}_{\mathrm{g}}-\mathrm{T}_{\mathrm{g}, \text { out }}\right)$

Where, $T_{g}$ is the hot gas temperature, which is estimated from the difference between the hot gas temperature at the evaporator outlet and the drum saturation temperature.

$\mathrm{T}_{\text {pin }}=\mathrm{T}_{\mathrm{g}}-\mathrm{T}_{\text {sat } @ \text { Drum pressure }}$

Drum inlet water temperature $\left(T_{2}\right)$ is also estimated from the temperature difference between the drum inlet water temperature and the saturation temperature.

$\mathrm{T}_{\text {app }}=\mathrm{T}_{\text {sat } @ \text { Drum pressure }}-\mathrm{T}_{2}$

\section{Absorption chiller}

Double-acting absorption chiller includes evaporator, absorber, generator, condenser, expansion valves and pump. Each of the chiller components is assumed to be a control volume, and the thermodynamic equations and mass and energy balance for each are written as follows [12-15]:

$\sum \dot{\mathrm{m}}_{\text {in }}=\sum \dot{\mathrm{m}}_{\text {out }}$

$\sum(\dot{\mathrm{m}} . \mathrm{x})_{\text {in }}=\sum(\dot{\mathrm{m}} . \mathrm{x})_{\mathrm{out}}$

$\dot{Q}-\dot{\mathrm{W}}=\sum \dot{\mathrm{m}}_{\text {out }} \mathrm{h}_{\text {out }}-\sum \dot{\mathrm{m}}_{\text {in }} \mathrm{h}_{\text {in }}$

\section{SIMULATION HYPOTHESES}

1. All inspections have been carried out assuming stable conditions.

2. The condenser outlet is in saturated liquid state and the evaporator outlet is in saturated steam state.

3. The solution of the adsorbent, the single-acting system generator, and the low-pressure and high-pressure generators of the two-acting system are at their equilibrium concentration at the targeted temperature.

Published By:

Blue Eyes Intelligence Engineering

\& Sciences Publication 
4. The reduction of pressure by friction in heat exchangers and pipes connecting system components is negligible.

5. Direct heat transfer of system components to the environment is neglected.

6. The feed water flow is equally distributed between the evaporators.

7. The temperature difference between the evaporators is considered the same.

\section{VALIDATION OF RESULTS}

\section{A. Validation of the thermodynamic simulation(I)}

Validation of the thermodynamic simulation has done for a single-acting absorption cycle. The results of Kaushik and Aurora study have been used to validate the thermodynamic simulation of a single-acting absorption chiller [16]. Table 1 compares the results of the present study with the study of Kaushik and Aurora.

Table-I: Validation of the thermodynamic simulation

\begin{tabular}{|c|c|c|c|}
\hline \multirow{2}{*}{ Components } & \multirow{2}{*}{ Symbol } & \multicolumn{2}{|c|}{ Energy Flow (kW) } \\
\cline { 3 - 4 } & & Current Research & Research [16] \\
\hline Generator & $\dot{Q}_{\text {gen }}$ & 3076.40 & 3095.70 \\
\hline Absorber & $\bar{Q}_{\text {abs }}$ & 2942.66 & 2945.27 \\
\hline Condenser & $\bar{Q}_{\text {cond }}$ & 25005.91 & 2505.91 \\
\hline Evaporator & $\bar{Q}_{\text {eva }}$ & 2355.45 & 2355.45 \\
\hline Pump & $\overline{\boldsymbol{W}}_{\text {p,ac }}$ & 0.0326 & 0.0314 \\
\hline $\begin{array}{c}\text { Coefficient of } \\
\text { Performance }\end{array}$ & COP & 0.7656 & 07609 \\
\hline
\end{tabular}

B. Validation of the thermodynamic simulation(II)

Validation of the thermodynamic simulation has done for a double-acting absorption cycle. To validate the thermodynamic simulation of double-acting absorption chiller, the results of Gomri and Hakimi research [17] have been used (Table 2).

Table-II: Validation of the results for double-acting absorption cycle

\begin{tabular}{|c|c|c|c|}
\hline Components & Symbol & \multicolumn{2}{|c|}{ Energy Flow (kW) } \\
\cline { 3 - 4 } & & Simulated Model & $\begin{array}{c}\text { Designed } \\
\text { Model [17] }\end{array}$ \\
\hline $\begin{array}{c}\text { High Pressure } \\
\text { Generator }\end{array}$ & $\oint_{\text {hpg }}$ & 245.407 & 252.407 \\
\hline Condenser & $\oint_{\text {cond }}$ & 167.707 & 167.205 \\
\hline Evaporator & $\oint_{\text {eva }}$ & 300 & 300 \\
\hline Absorber & $\oint_{\text {abs }}$ & 384.796 & 385.236 \\
\hline Pump & $W_{\text {p,ac }}$ & 0.058 & 0.000 \\
\hline $\begin{array}{c}\text { Coefficient of } \\
\text { Performance }\end{array}$ & COP & 1.220 & 1.189 \\
\hline
\end{tabular}

\section{DISCUSSION AND CONCLUSION}

\section{A. Performance changes with number of evaporators}

As the number of evaporators increases in the same temperature range (while the temperature difference between the first and last evaporators is constant), the coefficient of performance increases as shown in Figure 3.

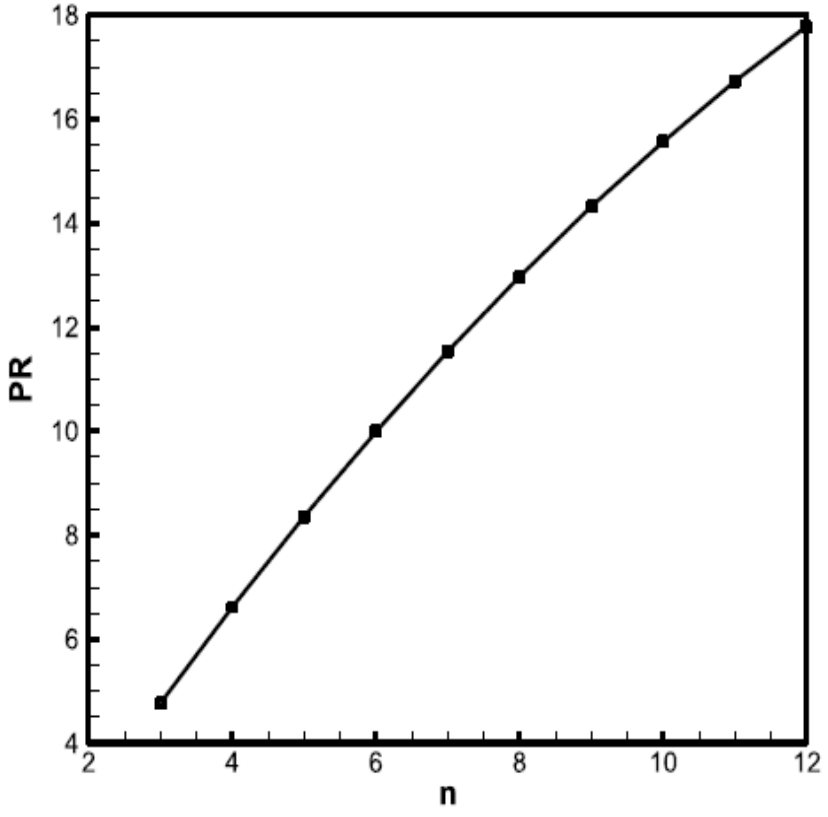

Fig.3. Changes in the performance ratio (PR) with the number of evaporators in the series-parallel arrangement

\section{B. Effect of heating steam temperature on PR}

As the latent heat of vaporization decreases with increasing temperature, increasing the temperature of the heating steam (exhaust steam) reduces the water mass and performance ratio (Figure 4).

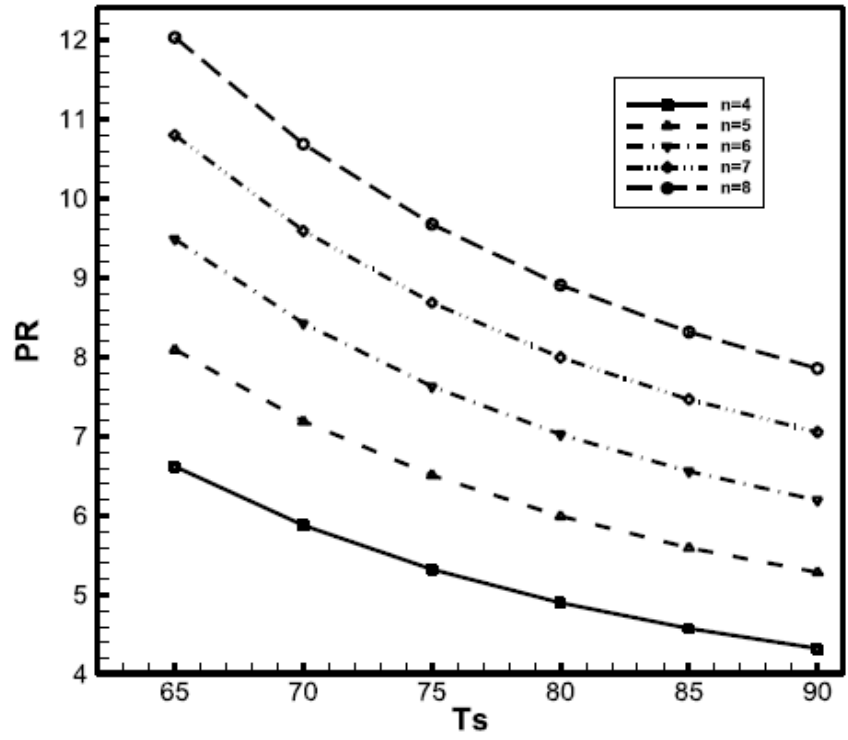

Fig.4. Effect of heating steam temperature on the performance ratio in a number of different stages

\section{The effect of first evaporator temperature on} performance ratio

As the temperature of the first evaporator rises, which also increases the temperature difference between the evaporators, the amount of water mass decreases.

As a result, less steam is produced and the efficiency is reduced (Figure 5). 


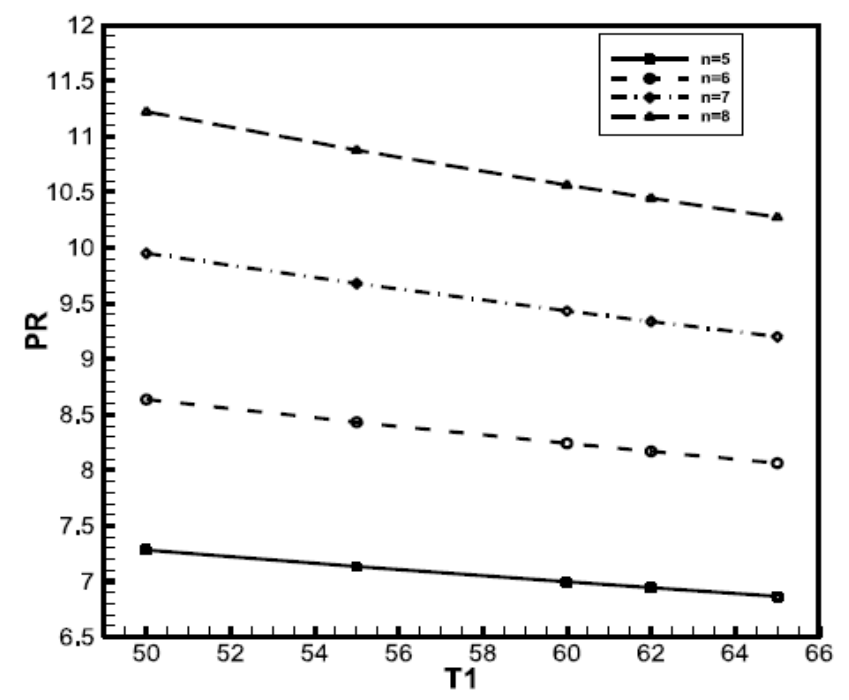

Figure 5. Changes in the performance ratio with the temperature of the first evaporator

\section{Simulation of mixed power generation and cooling systems}

This simultaneous system is modeled using the governing equations in EES software. In this way, initially in a CHP system with power generation rate of $2 \mathrm{MW}$ was considered to direct the outlet gas of turbine into the recycling boiler. The outlet gas is flowing with $13.3 \mathrm{Kg} / \mathrm{s}$ at a temperature of $500 \circ \mathrm{C}$. The recycling boiler is producing the steam with $4.089 \mathrm{Kg} / \mathrm{s}$ at a temperature of $179.9 \circ \mathrm{C}$.

The resulting steam can be used in an absorption chiller to achieve the amount of water and cold load as well. Considering this, different views can be considered for this mixed system, which are referred to below.

\section{- The first view}

In this view, $100 \%$ of the resulting steam mass with a temperature of 179.9 is assigned to the absorption chiller and the cold load produced in the single-acting chiller Qgen = $225.07 \mathrm{~kW}$ and in the double-acting chiller obtained as Qgen $=40.48 \mathrm{~kW}$.

\section{- The second view}

In this view, $70 \%$ of the resulting steam mass is desalted and $30 \%$ of the desired steam mass is given to the absorption chiller, which produces $M_{d}=19.0616 \mathrm{~kg} / \mathrm{s}$ of fresh water and the cooling load produced in single-acting chiller Qgen= $67.52 \mathrm{kw}$ and in double-acting chiller obtained as Qgen = $12.14 \mathrm{kw}$.

\section{- The third view}

In this view, $30 \%$ of the steam mass is given to the desalination device and $70 \%$ to the absorption chiller for cooling production, which $\mathrm{Md}=8.1693$ fresh water is produced and the cooling load in the single-acting chiller will be obtained as Qgen $=157.55 \mathrm{kw}$ and in the double-acting chiller as Qgen $=28.33 \mathrm{kw}$.

\section{CONCLUSION}

In this research work, the simulation of mixed power generation system has been investigated for a single-acting and double-acting absorption cooling systems. It has found that the proposed mixed system will be an alternative solution for the energy shortage. In the current work, the validation perfumed and after validating the simulation results of each part of the mixed system, the performance of the mixed system has been studied in three different views in terms of power generation and cooling production using single and double-acting absorption cooling system. The design of a physical model of a mixed system of power generation and absorption cooling on a laboratory scale is proposed for future experimental researches.

\section{REFERENCES}

1. Salcedo, R., et al. "Multi-objective optimization of solar Rankine cycles coupled with reverse osmosis desalination considering economic and life cycle environmental concerns." Desalination 286 (2012): 358-37.

2. Sanaye S, Asgari S. Four E analysis and multi-objective optimization of combined cycle power plants integrated with Multi-stage Flash (MSF) desalination unit. Desalination 2013;320:105e17.

3. Alzahrani, Abdulaziz, Jamel Orfi, and Zeyad Alsuhaibani. "Performance analysis of a gas turbine unit combined with MED-TVC and RO desalination systems." Desalination and Water Treatment 55.12 (2015): 350-3357.

4. Loutatidou, Savvina, and Hassan A. Arafat. "Techno-economic analysis of MED and RO desalination powered by low-enthalpy geothermal energy." Desalination 365 (2015): 277-292.

5. Gabriel, Kerron J., Mahmoud M. El-Halwagi, and Patrick Linke. "Optimization across the Water- Energy Nexus for Integrating eat, Power, and Water for Industrial Processes, Coupled with Hybrid Thermal- Membrane Desalination." Industrial \& Engineering Chemistry Research 55.12 (2016): 3442-3466.

6. Mokhtari, Hamid, and Mehdi Sepahvand. "Thermoeconomic and exergy analysis in using hybrid systems (GT+ MED+ RO) for desalination of brackish water in Persian Gulf." Desalination 399 (2016): 1-15.

7. Y.wang,Y.shi,M.Ni,Cai, A micro tri-generation system based on direct flame fuel cells for residential applications. International Journal of Hydrogen Energy, Vol.39, No.11,PP .5996-6005,2014.

8. Taheri,Hamed, and Iraj Naser, Study and Simulation of Optimized Cycle for Water, Electricity \& Colling Using Low Pressure Vapor, 2nd Scientific Conference of Processes, Tehran, 2014.

9. Tavakuli Dastjerd,Fatima, and Mohammad Hussain Shafiyee, Optimization of CCHP Systems through Comparative Study based on Cost in Iran and Mexico, 2nd International Scientific Conference of New Technologies, Mashhad, Firdausi University, 2016.

10. Cangel,Y.A.and Blose,M.A,(1998)."Thermodynamics an engineering approach".Megraw-Hill,network.

11. Sanaye, Sepehr, and Saeid Asgari. "Analysis and optimization of integrated gas turbine, heat recovery steam generator and multi-effect thermal vapour compression desalination plant." Proceedings of the Institution of Mechanical Engineers, Part A: Journal of Power and Energy 227.8 (2013): 919-936.

12. Huicochea, Armando, et al. "Thermodynamic analysis of a tri-generation system consisting of a micro gas turbine and a double effect absorption chiller." Applied Thermal Engineering 31.16 (2011): 3347-3353.

13. H. M. Attorney, H. T. El-Dessouky, R. S. Faibish, P. J. Gowin, Evaluating the economics of desalination, Chemical Engineering Progress, Vol. 98, No. 12,pp. 32-40, 2002.

14. M. M. Ashour, Steady state analysis of the Tripoli West LT-HT-MED plant, Desalination, Vol. 152, No. 1, pp. 191-194, 200.

15. F. Alasfour, M. Darwish, A. B. Amer, Thermal analysis of ME-TVC+ MEE desalination systems, Desalination, Vol. 174, No. 1, pp. 39-61, 2005

16. Kaushik S.C., Arora A., Energy and exergy analysis of single effect and series flow double effect water-lithium bromide absorption refrigeration systems, International Journal of Refrigeration 2009; 32:1247-1258.

17. Gomri R.,Hakimi R.,Second law analysis of double effect vapor absorption cooler system, Energy Conversion and Management 2008;49:3343-3348. 


\section{AUTHORS PROFILE}

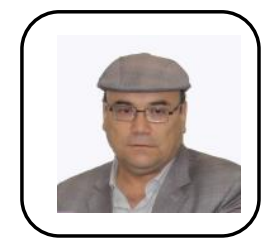

Prof. Dr. Aref Naimzad, received a Ph.D. degree in Mechanical Engineering from Trabiat Modares University, Iran. He has been a Professor in Kabul University from 2000 to date and working as Dean of Engineering Faculty of Kabul University from 2018 up to date. He has participated in 16 international scientific conferences in Germany, Singapore, China, Russia, Japan, Turkey, China and Iran. Currently, $\mathrm{He}$ is the membership of Research, Compilation and Translation Committee of Ministry of Higher Education (MoHE) of Afghanistan.

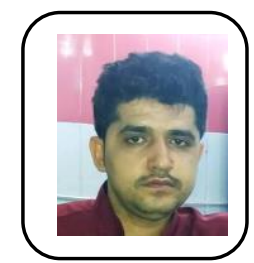

Murtaza Omid, received a B.Sc. degree in Mechanical Engineering, He is currently working as a R\&D research member with Green Energy Research Center. He has participated in local and international scientific conferences. He is going to start his master studies related to the Manufacturing Engineering on September 2020. 